\title{
SISTEM PENYIRAMAN TANAMAN ANGGREK MENGGUNAKAN SENSOR KELEMBABAN DENGAN PROGRAM BORLAND DELPHI 7 BERBASIS MODUL ARDUINO UNO R3
}

\author{
Happy Nugrahaning Widhi, Heru Winarno \\ Program Studi Diploma III Teknik Elektro \\ Fakultas Teknik Universitas Diponegoro
}

\begin{abstract}
Happy Nugrahaning Widhi, Heru Winarno, in paper orchid plant watering system using humidity sensor used Borland Delphi 7 based on arduino uno R3 explain that the utilization of variable moisture for plant watering orchids do not fully utilized. At this time watering orchids is still done manually. It certainly took a lot of time, by making a watering system based on this moisture will save time. To determine the value of temperature and humidity used SHT-11 module is capable of detecting the temperature from $-40 \mathrm{C}$ to $123,8^{\circ} \mathrm{C}$ and relative humidity from $0 \% \mathrm{RH}$ to $100 \% \mathrm{RH}$. Watering plants Phalaenopsis amabilis orchids species do when the SHT-11 detects the humidity inside the orchids house below $60 \%$ RH. Watering is carried out by spraying water from above directly into the plant's roots. The method of watering is intended that the water can be poured directly absorbed by the plant. This control system controlled by arduino uno microcontroller. As for the computer control system, used Borland Delphi 7 to make aplication for control. So this watering system is divided into two they are automated systems and control through computer system
\end{abstract}

Keywords: Module SHT-11, Arduino UNO, Borland Delphi 7.

\section{PENDAHULUAN}

Pada saat ini budidaya anggrek mulai banyak di budidayakan di Indonesia sebagai tanaman bunga hias komersial. Tanaman anggrek merupakan tipe tanaman yang memiliki kecepatan tumbuh yang relatif lambat sehingga diperlukan perawatan khusus agar anggrek bisa tumbuh dengan baik. Pada umumnya budidaya anggrek bulan secara massal memerlukan rumah naungan untuk menciptakan kondisi iklim mikro yang sesuai dengan habitat anggrek itu sendiri.

Berdasarkan observasi yang telah dilakukan anggrek dapat berkembang dengan baik di Semarang yang memiliki cuaca yang panas. Hal ini dapat ditangani dengan dengan pembangunan rumah tanaman dengan atap paranet ataupun plastic $U V$ serta penyiraman berdasarkan cuaca dimana ketika cuaca panas yang berarti kelembaban kering yaitu kelembaban di bawah 60\% RH.

Sistem penyiraman yang dilakukan di tempat penangkaran anggrek Semarang masih dilakukan secara manual. Dimana hal ini dapat menyita banyak waktu dan tenaga untuk melakukan penyiraman secara manual berdasarkan permasalahan tersebut maka dibuatlah "Sistem Penyiraman Tanaman Anggrek Menggunakan Sensor Kelembaban Dengan Program Borland Delphi 7 Berbasis Modul Arduino Uno R3”. Selain sistem ini berjalan otomatis melakukan penyiraman ketika kelembaban di bawah 60\% RH, sistem ini juga dapat dikontrol dan dimonitoring dengan komputer.

\section{PERENCANAAN SISTEM}

Blok diagram secara keseluruhan dari sistem ditunjukan pada Gambar 1. Sistem kerja alat ini terbagi menjadi dua sistem yaitu sistem kontrol dan sistem otomatis. Arduino mendapat input dari sensor SHT-11 berupa suhu dan kelembaban. Kemudian Arduino mengolah input tersebut untuk ditampilkan ke LCD dan dikirim secara serial ke komputer untuk ditampilkan ke aplikasi Delphi. Pada mode otomatis ketika suhu diatas $28 \mathrm{C}$ maka aktuator kipas 1 dan kipas 2 menyala dan ketika kelembaban dibawah 60\% RH maka buzzer nyala dan pompa DC nyala untuk melakaukan penyiraman. Sedangkan pada saat mode Kontrol dapat dilakuan kontrol terhadap aktuator melalui aplikasi yang telah dibuat menggunakan Delphi.

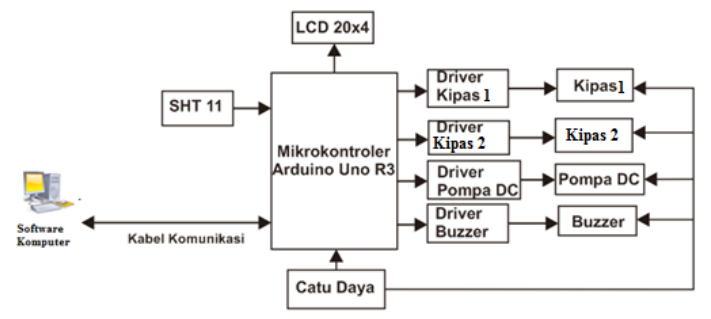

Gambar 1. Blok Diagram Sistem

\section{Rangkaian Sensor SHT-11}

Sensor ini terdiri dari elemen polimer kapasitif (digunakan untuk mengukur kelembaban), pita regangan sebagai sensor temperatur, 14 bit ADC (Analog to Digital Converter), dan interface serial 2 kabel. Didalamnya juga terdapat memory kalibrasi yang digunakan untuk menyimpan koefisien kalibrasi hasil pengukuran sensor. Data hasil pengukuran dari SHT11 ini berupa digital logic yang diakses secara serial. 


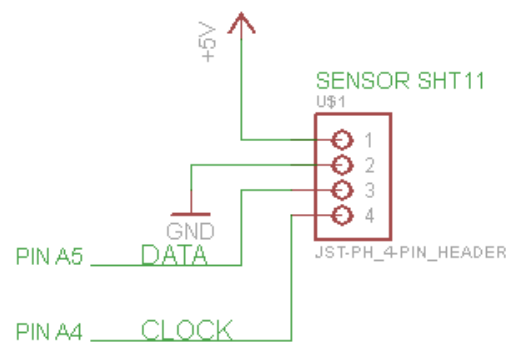

Gambar 2. Rangkaian Sensor SHT11 ke PIN Arduino

Sensor ini terdiri dari 4 pin dengan spesifikasi seperti pada tabel 1.

Tabel 1. Konfigurasi Pin SHT-11

\begin{tabular}{lll}
\hline Pin & Name & Coment \\
\hline GND & GND & GROUND \\
A5 & DATA & Serial data bedirectional \\
A4 & SCK & Serial clock input \\
VCC & VCC & Suplay \\
\hline
\end{tabular}

\section{Arduino Uno R3}

Arduino uno R3 ini menggunakan mikrokontroler ATmega328 yang memiliki 14 pin I/O digital (6 pin diantaranya dapat digunakan sebagai output PWM), 6 analog dan clock yang digunakan $16 \mathrm{MHz}$ (xtal), port usb, jack power supply, dan tombol reset.

Fungsi mikrokontroler dalam alat ini adalah sebagai pusat pengendali mengolah inputan suhu dan kelambaban dari sensor. Melakukan pengolahan inputan serta menghasilkan output berupa perintah ke aktuator.

\section{Rangkaian Aktuator}

Rangkaian aktuator terdiri dari rellay driver dan beban yang dikontrol seperti kipas, pompa DC dan buzzer. Rangkaian rellay driver terdiri dari relay transistor, dioda, resistor dan LED. Cara kerja rellay driver ini yaitu ketika mikro memberikan trigger LOW (0) maka transistor aktif sebagai saklar $\mathrm{ON}$ dan melewatkan arus $\mathrm{Ib}=>\mathrm{Ic} / \beta$ yang kemudian mengaktifkan rellay. Setelah rellay aktif maka beban akan mendapatkan suplay. Dan saat mikro memberikan trigger HIGH (1) maka transistor berperan sebagai saklar Off $(\mathrm{Ib}=0)$ dan rellay kembali ke posisi Normally close. Hal ini menimbulkan arus balik yang dihasilkan dari kumparan rellay, disinilah fungsi peranan dioda sebagai proteksi yaitu memblok arus balik tersebut agar transistor terlindungi.

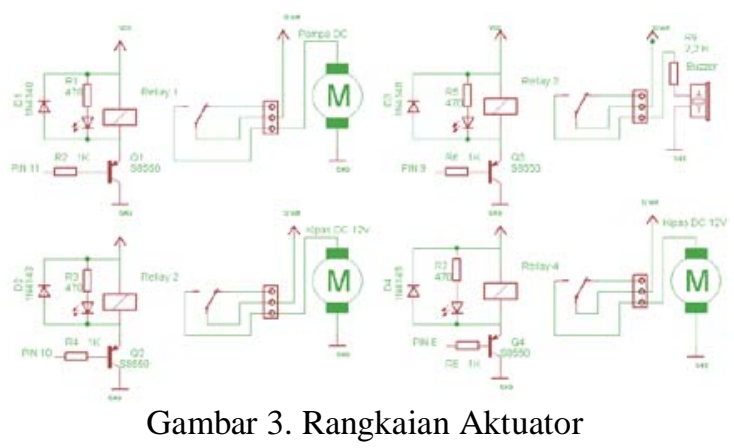

Registrasi Pin Mikrokontroler pada aktuator

- Pin 11 arduino terhubung dengan relay driver 1 untuk mengontrol pompa DC.

- $\quad$ Pin 10 arduino terhubung dengan rellay driver 2 untuk mengontrol kipas 1.

- $\quad$ Pin 9 arduino terhubung dengan rellay driver 3 untuk mengontrol buzzer (sebagai alarm).

- $\quad$ Pin 8 arduino terhubung dengan rellay driver 4 untuk mengontrol kipas 2.

\section{Rangkaian LCD}

Modul Liquid Crystal Display (LCD) merupakan modul display yang serbaguna, karena dapat digunakan untuk menampilkan berbagai tampilan baik berupa huruf, angka dan karakter lainnya serta dapat menampilkan berbagai macam tulisan maupun pesan-pesan pendek lainnya. Rangkaian penampil LCD pada sistem ini difungsikan untuk menampilkan suhu, kelembaban dan mode sistem yang sedang berjalan.

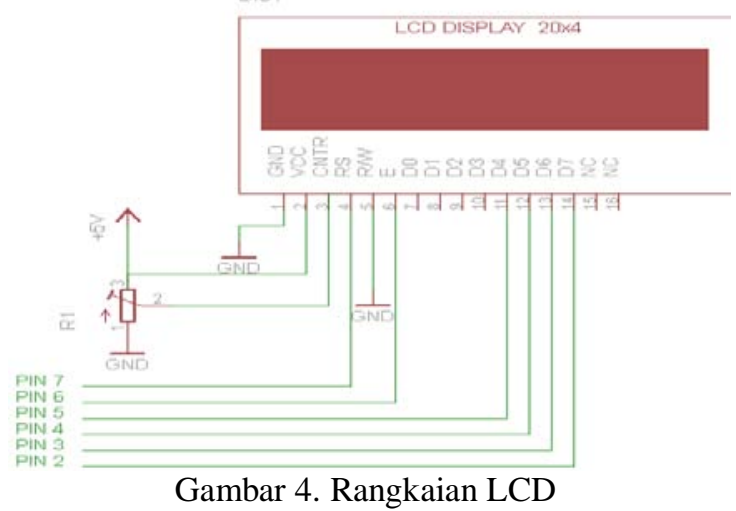

Disini hubungan pin-pin dari LCD ke mikrokontroler Arduino Uno R3 :

- Pin $5 \mathrm{~V}$ terhubung ke pin $5 \mathrm{~V}$ dari mikrokontroler.

- GND terhubung ke ground sistem mikrokontroler.

- $\quad$ Pin RS (register select) terhubung ke pin 7 pada mikrokontroler.

- $\quad$ Pin E (enable) terhubung ke pin 6 pada mikrokontroler.

- $\quad$ Pin D4,D5,D6,D7 terhubung ke pin 5, 4, 3, 2 pada mikrokontroler 


\section{Aplikasi Inerface Program Delphi 7}

Program Borland Delphi 7 di gunakan untuk membuat aplikasi interface komputer. Tampilan aplikasi terdiri dari tampilan suhu-kelembaban, informasi mode sistem, tombol sebagai kontrol, tampilan database dan petunjuk pemakaian aplikasi. Gambar 6 adalah tampilan aplikasi yang telah dibuat.

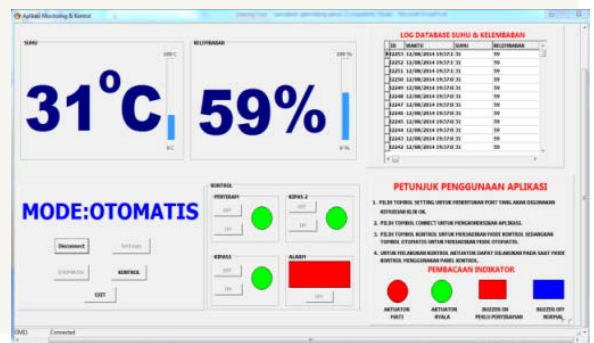

Gambar 6. Tampilan Aplikasi

\section{PENGUKURAN DAN PENGUJIAN \\ Pengujian Sensor SHT-11}

Pengujian sensor ditunjukkan pada tabel 1 . Sdangkan gambar 7 menunjukkan perbandingan pengukuran sensor dengan alat ukur dan sistem.
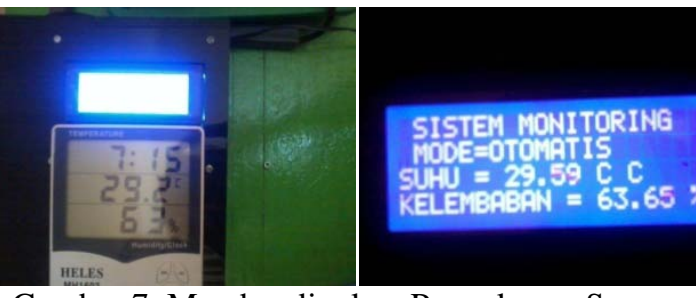

Gambar 7. Membandingkan Pengukuran Sensor

Berdasarkan hasil pengujian Tabel 2 sensor SHT-11 baik dalam membaca suhu dan kelembaban hal ini terbukti dengan selisih yang tak begitu banyak dengan alat ukur yang telah ada.

\section{Pengujian Sistem Otomatis}

Pengujian sistem otomatis ini dilakukan di luar ruangan saat cuaca panas. Hasil pengujian ditunjukkan pada tabel 3.

Berdasarkan tabel 3 dapat dikatakan sistem otomatis telah bekerja dengan baik. Ketika suhu diatas $28 \mathrm{C}$ maka kipas 1 dan kipas 2 nyala untuk menurunkan suhu. Ketika kelembaban di bawah $60 \%$ RH maka alarm berbunyi dan kemudian dilakukan penyiraman dengan menggunakan pompa sampai kelembaban mencapai 60\% RH.

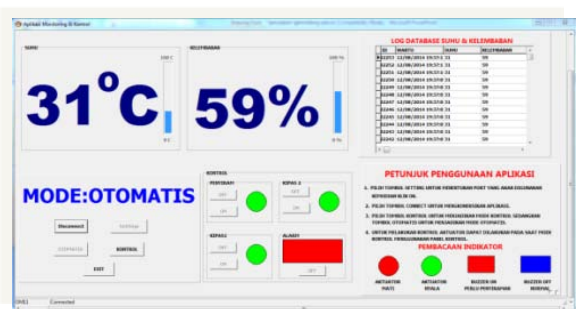

Gambar 8. Tampilan Sistem Otomatis Melalui Komputer

\section{Pengujian Sistem Kontrol Aplikasi}

Pengujian Sistem kontrol dengan aplikasi yang telah dibuat dengan program delphi 7 dengan menghubungkan mikrokontroler dengan komputer. Hasil pengujian aplikasi ditunjukkan pada tabel 4.

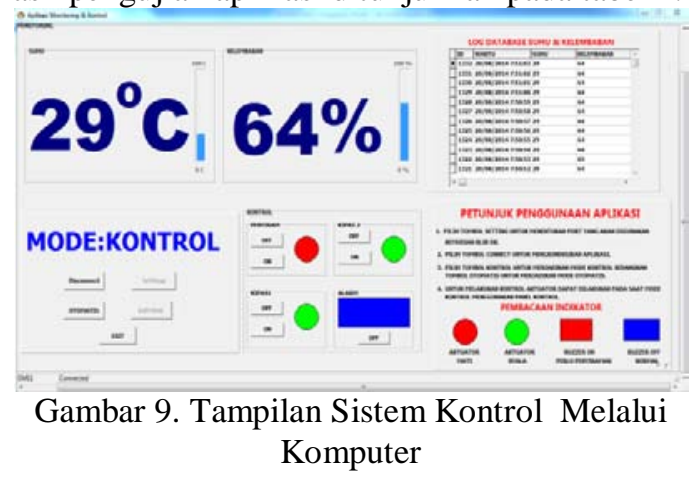

Data suhu dan kelembaban berhasil termonitor dan masuk ke database MS.Access dengan baik. Berdasarkan Tabel 4 kontrol yang dilakukan melalui aplikasi berhasil dengan baik

\section{KESIMPULAN}

- Mikrokontroler Arduino menerima inputan data dari sensor suhu dan kelembaban kemudian mengolahnya dan memberikan outputan berupa perintah melalui rellay driver.

- Di dalam sensor SHT-11 terdapat kapasitas polimer sebagai sensor kelembaban dan sebuah pita regangan sebagai sensor temperature. Kedua output sensor ini dihubungkan pada ADC 14 bit yang berada di dalam sensor untuk dirubah ke data digital. Data digital ini yang nanti diminta oleh mikrokontroler yang selanjutya akan dirubah ke besaran fisik suhu dan kelembaban.

- Rangkain rellay driver yang digunakan merupakan rengkaian rellay aktif Low. Rellay akan aktif ketika diberi logika Low (0) ini dikarenakan karena transistor yang digunakan pada rangkaian rellay driver adalah transistor PNP.

- Proses otomatisasi penyiraman tanaman anggrek dapat berjalan dengan baik berdasarkan nilai kelembaban yang dideteksi oleh sensor SHT-11 yakni ketika kelembaban bernilai di bawah 60\% RH.

- Proses penurunan suhu cukup sulit karena desain miniatur rumah kaca yang terbuat dari bahan acrylic, dimana bahan ini menyerap panas.

- Aplikasi monitoring dan kontrol suhu dan kelembaban pada rumah kaca tanaman anggrek berjalan dengan baik. 
DAFTAR PUSTAKA

1. Andiani, Yulia.2012. Usaha Pembibitan Anggrek. Yogyakarta: Pustaka Baru Press.

2. Anonimus. 2010. Dioda Forward Bias dan Forward Reverse. Diunduh dari http://www.elektronikabersama.web.id/2011/0 5/dioda-forward-bias-dan-reverse-bias.html Selasa, 3 Juni 2014 jam 09.38

3. Anonimus. 2012. Mengenal Arduino. Diunduh dari http://www.sahabatinformasi.com/2012/07/mengenal-arduinouno.html Selasa, 3 Juni 2014 jam 18.12

4. Anonimus. 2012. Prinsip Kerja Motor DC. Diunduh dari http://elektronikadasar.web.id/teori-elektronika/prinsip-kerjamotor-dc/ Rabu, 4 Juni 2014 jam 15.12

5. Anonimus. 2012. Teori Relay Elektro Mekanik. Diunduh dari http://elektronikadasar.web.id/teori-elektronika/teori-relayelektro-mekanik/ Selasa, 3 Juni 2014 jam 10.12

6. Anonimus.2013. Pengertian dan Dasar Fungsi Transitor. Diunduh dari http://dasarelektronika.com/pengertian-danfungsi-transistor/Selasa, 3 Juni 2014 jam 10.50

7. Aprianto, Aris. 2011. Jurnal: Rancang Bangun Penyiraman Tanaman Anggrek Menngunakan Sensor Kelembaan dengan Energi Alternatif Sinar Matahari.Surabaya: Politeknik Elektro Negeri Surabaya.

8. Fahmizal. 2010. Akses Sensor Suhu dan Kelembaban SHT-11. Diunduh dari http://fahmizaleeits.wordpress.com/2010/08/2 9/akses-sensor-suhu-dan-kelembaban-sht11berbasis-mikrokontroler/ Selasa, 3 Juni 2014 jam 19.05

9. Faris. 2011. Prinsip Kerja Power Suply. Diunduh dari http://forumelektronika indonesia.blogspot.com/2012/11/prinsip-kerjapower-supply.html Senin, 2 Juni 2014 Jam 10.09

10. Kadir, Abdul.2012. Panduan Praktis Mempelajari Aplikasi Mikrokontroler \& Pemrograman Menggunakan Arduino. Yogyakarta: Andi.

11. Kusnassriyanto.2011. Belajar Program Delphi.Bandung: Modula.

12. Rudi. 2012. Rangkaian catudaya Switching. Diunduh dari http://servicecente rcomputer.blogspot.com/2011/09/cara-kerjacatu-daya-switching.html Senin, 2 juni 2014 jam 11.08

13. Sensirion. 2010. Datasheet SHT-1X. Diunduh dari d http://www.sensirion.com /fileadmin/user_upload/customers/sensirion/D okumente/Humidity/Sensirion_Humidity_SH T1x_Datasheet_V5.pdf : Selasa, 8 Juli 2014 jam 10.4

14. Surono. 1988. Tata Tulis Karya Ilmiah Bahasa Indonesia.Semarang : Fakultas Sastra Universitas Diponegoro.

Tabel 2. Pengujian Sensor SHT-11

\begin{tabular}{|c|c|c|c|c|c|c|}
\hline \multirow[b]{2}{*}{ Tanggal } & \multirow[b]{2}{*}{ Jam } & \multicolumn{2}{|c|}{ Suhu ( C ) } & \multicolumn{2}{|c|}{ Kelembaban ( \%RH ) } & \multirow[t]{2}{*}{ Keterangan } \\
\hline & & SHT-11 & Alat Ukur & SHT-11 & Alat Ukur & \\
\hline \multirow{5}{*}{$13-07-2014$} & 11.30 & 30,58 & 30,2 & 69,32 & 69 & \multirow{5}{*}{$\begin{array}{l}\text { Di luar } \\
\text { ruangan } \\
\text { cuaca } \\
\text { mendung. }\end{array}$} \\
\hline & 11.45 & 31,53 & 30,3 & 68,7 & 68 & \\
\hline & 12.00 & 29,79 & 30,4 & 78,34 & 78 & \\
\hline & 12.15 & 27,94 & 28,3 & 79,86 & 80 & \\
\hline & 10.45 & 44,54 & 44,9 & 26,68 & 27 & \\
\hline \multirow{6}{*}{$19-07-2014$} & 11.00 & 44,25 & 44,4 & 26,25 & 26 & \multirow{5}{*}{$\begin{array}{c}\text { Di luar } \\
\text { ruangan } \\
\text { cuaca cerah } \\
\text { panas }\end{array}$} \\
\hline & 11.15 & 45,05 & 44,8 & 25,4 & 25 & \\
\hline & 11.30 & 45,2 & 45 & 25,57 & 25 & \\
\hline & 11.45 & 45,56 & 45,4 & 25,20 & 25 & \\
\hline & 12.00 & 46,25 & 45,8 & 24,89 & 25 & \\
\hline & 13.00 & 30,99 & 30,6 & 61,8 & 62 & \multirow{6}{*}{$\begin{array}{l}\text { Di dalam } \\
\text { ruangan. }\end{array}$} \\
\hline \multirow{5}{*}{$19-07-2014$} & 13.15 & 30,2 & 30,3 & 60,3 & 60 & \\
\hline & 13.30 & 30,15 & 30,1 & 60,47 & 60 & \\
\hline & 13.45 & 30 & 29,9 & 60,78 & 61 & \\
\hline & 14.00 & 30,05 & 30,1 & 60,9 & 61 & \\
\hline & 14.15 & 30,14 & 30,1 & 61,2 & 60 & \\
\hline
\end{tabular}


Tabel 3. Pengujian Sistem Otomatis

\begin{tabular}{|c|c|c|c|c|c|c|c|}
\hline \multirow[b]{2}{*}{ NO } & \multirow{2}{*}{$\begin{array}{c}\text { Tanggal } \\
\text { 21-07-2014 } \\
\text { Jam }\end{array}$} & \multicolumn{2}{|r|}{ SHT-11 } & \multirow[b]{2}{*}{ Pompa } & \multirow[b]{2}{*}{ Kipas 1} & \multirow[b]{2}{*}{ Alarm } & \multirow[b]{2}{*}{ Kipas 2} \\
\hline & & Suhu & Kelembaban & & & & \\
\hline 1 & 11.45 & 39,8 & 37,56 & Nyala & Nyala & Nyala & Nyala \\
\hline 2 & 11.47 & 34,86 & 56,34 & Nyala & Nyala & Nyala & Nyala \\
\hline 3 & 11.51 & 33,59 & 57,14 & Nyala & Nyala & Nyala & Nyala \\
\hline 4 & 11.54 & 32,9 & 63,55 & Mati & Nyala & Nyala & Mati \\
\hline 5 & 12.00 & 31,74 & 54,76 & Nyala & Nyala & Nyala & Mati \\
\hline 6 & 12.06 & 31,47 & 79,20 & Mati & Nyala & Nyala & Mati \\
\hline
\end{tabular}

Tabel 4. Hasil Pengujian Sistem Kontrol

\begin{tabular}{lccc}
\hline Tombol & Tekan & Indikator & Status Aktuator \\
& ON/OFF & & \\
\hline Penyiram & ON & Hijau & Pompa DC menyala \\
& OFF & Merah & Pompa DC mati \\
Kipas 1 & ON & Hijau & Kipas 1 menyala \\
& OFF & Merah & Kipas 2 mati \\
Kipas2 & ON & Hijau & Kipas 2 menyala \\
& OFF & Merah & Kipas 2 mati \\
Alarm & OFF & Biru & Buzzer mati \\
\hline
\end{tabular}

